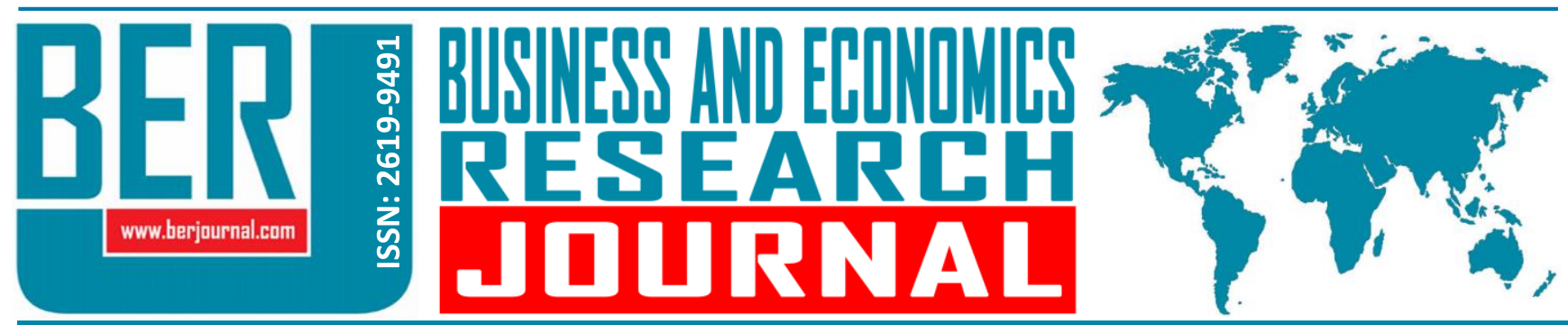

Business and Economics Research Journal Vol. 11, No. 3, 2020, pp. 703-712 doi: 10.20409/berj.2020.278

\section{Hangi Sektörlerde Getiri Öngörülebilirliği İçin Tarihsel Fiyatlar Kullanılabilir? Otomatik Portmanteau Testi ile Borsa İstanbul Üzerine Ampirik Bir Çalışma}

\section{Oktay Ozkan}

Öz: Bu çalışmanın amacı Türkiye'deki farklı sektörlerin getiri öngörülebilirliğini diğer bir ifadeyle zayıf formdaki piyasa etkinliğini karşılaştırmaktır. Bu amaçla Borsa istanbul bünyesinde bulunan 19 birincil sektör endeksinin 04.07.2000-07.02.2020 tarihleri arasındaki günlük verileri kullanılarak 2 yıllık alt örneklem büyüklügü ile otomatik portmanteau testi ile analizler gerçekleştirilmiştir. Analizler sonucunda Ulaştırma, Sigorta, Elektrik ve Metal Ürünler ve Makineler sektörlerinin getiri öngörülebilirlik dönemlerinin daha fazla olduğu ve dolayısılla zayıf formdaki etkinliklerinin diğer sektörlere göre daha düşük olduğu anlaşılmıştır. Ayrıca getiri öngörülebilirlik dönemlerinin en az olduğu diğer bir ifadeyle diğer sektörlere göre daha fazla zayıf formda etkinliğe sahip olan sektörlerin ise Yiyecek ve içecek, Bankalar, Toptan Satış ve Perakende Ticaret ve Odun, Kağıt ve Baskı olduğu belirlenmiştir.

\section{In Which Sectors Can Historical Prices Be Used for Return Predictability? An Empirical Study on Istanbul Stock Exchange with Automatic Portmanteau Test}

Abstract: The aim of this study, to compare return predictability in other words, the weak form of market efficiency of different sectors in Turkey. For this purpose, analyses were carried out by automatic portmanteau test with a 2-year sub-sample size using the daily data between 19.04.2000-07.02.2020 of 19 primary sector indexes within Borsa Istanbul. As a result of the analyses, it was understood that Transportation, Insurance, Electricity, and Metal Products Machinery sectors have higher return predictability periods and therefore their weak form market efficiency is lower than other sectors. In addition, it was determined that the sectors that have the least predictable periods of return, in other words, that have more weak form efficiency than other sectors, are Food Beverage, Banks, Wholesale and Retail Trade, and Wood Paper Printing.
Anahtar Sözcükler: Getiri Öngörülebilirliği, Otomatik Portmanteau Testi, Getiri, Etkin Piyasalar Hipotezi, Hisse Senedi Piyasası

JEL: C12, C22, G11, G14

$\begin{array}{ll}\text { Geliş } & : 19 \text { Şubat } 2020 \\ \text { Düzeltme } & : 05 \text { Mayıs } 2020 \\ \text { Kabul } & : 20 \text { Mayıs } 2020 \\ \text { Tür } & : \text { Araştırma }\end{array}$

Keywords: Return Predictability, Automatic Portmanteau Test, Return, Efficient Markets Hypothesis, Stock Market

JEL: C12, C22, G11, G14

Received : 19 February 2020

Revised : 05 May 2020

Accepted : 20 May 2020

Type : Research 


\section{Giriş}

Ekonomi ve finans alanlarındaki en temel sorulardan bir tanesi, finansal varlık fiyatlarının tarihsel fiyat verileriyle öngörülebilir olup olmadığıdır (Charles vd., 2017: 100). Bireysel ve kurumsal yatırımcılar, portföy yöneticileri ve akademisyenler sermaye piyasalarının gelişmeye başlamasıyla söz konusu soruya cevap bulmaya çalışmışlardır. Bu çalışmalar neticesinde finans alanında ortaya çıkan en etkili teorilerden biri olan Etkin Piyasalar Hipotezi ortaya çıkmıştır. Samuelson (1965) ve Fama'nın (1965) Etkin Piyasalar Hipotezi'ne göre varlık fiyatları tüm mevcut ve ilgili bilgileri tam ve anlık olarak yansıtmaktadır. Geçmiş fiyatlar ve getiriler bilgi setlerini içeren zayıf form etkinliğe göre, varlıkların gelecekteki fiyatları ve getirileri geçmiş fiyat bilgilerine dayanarak tahmin edilememektedir. Ayrıca varlık fiyatları bir martingale sürecini takip etmekte ve varlık getirileri martingal fark dizisi ile karakterize edilmektedir. Martingale fark dizisine göre, getirilerin ortalama olarak ilişkisiz olması gerekmektedir; fakat koşullu değişen varyans gibi daha yüksek bir sıra bağımlılığı gösterebilir. Martingale, varlık fiyatları için getirilerin bağımsız olduğu varsayılan rassal yürüyüş modelinden daha genel ve daha az kısıtlayıcıdır ${ }^{1}$ (Charles vd., 2015: 2). Bu çalışma da Lim ve Brooks (2010), Kim vd. (2011) ve Charles vd. (2011) çalışmalarında olduğu gibi çalışma kapsamındaki ilgili varlık getirilerin martingale fark dizisini takip edip etmediğini test etmektedir.

Bu çalışmanın temel amacı Borsa İstanbul bünyesindeki farklı sektörleri getiri öngörülebilirliği (zayıf formdaki piyasa etkinliği) açısından karşılaştırmaktır. Bu çalışma ayrıca bireysel ve kurumsal yatırımcılar ile portföy yöneticilerinin tarihsel fiyat hareketlerini kullanarak hangi sektörlerde başarılı olma şanslarını artırabileceklerini, hangi sektörde başarısız olma intimallerinin yüksek olabileceğini de ortaya koymaktadır. Bu amaç çerçevesi içerisinde Borsa İstanbul bünyesindeki 19 birincil sektör endeksinin 04.07.200007.02.2020 tarihleri arasındaki günlük verileri ile martingale fark dizisi özelliğini test etmek için Escanciano and Lobato (2009a) tarafından geliştirilen, normal dağılmayan veri setlerinde oldukça başarılı olan (Charles vd., 2011) ve aynı zamanda piyasanın etkinlik (etkinsizlik) veya varlık getirilerinin öngörülebilirlik derecesinin belirlenebilmesinde kullanılan test istatistiklerini de sağlayan (Charles vd., 2015: 4) otomatik portmanteau testi ile analizler gerçekleştirilmiştir ve elde edilen bulgular yorumlanmıştır.

Çalışmanın diğer bölümleri olan 2. Bölümde literatür taraması ile ilgili, 3. Bölümde analiz yöntemiyle ilgili, 4. Bölümde veri setleri ve ampirik bulgularla ilgili ve son bölümde ise sonuç ile ilgili bilgiler yer almaktadır.

\section{Literatür}

Çalışmanın bu bölümünde getiri öngörülebilirliği (zayıf formda piyasa etkinliği) kapsamında gerçekleştirilen çalışmalar ile ilgili literatür taraması yer almaktadır. Türkiye finansal piyasaları çerçevesinde gerçekleştirilen literatür taraması Tablo 1'de yer almaktadır.

Tablo 1. Türkiye Finansal Piyasaları Çerçevesinde Getiri Öngörülebilirliği veya Zayıf Formda Piyasa Etkinliğiyle Illgili Çalışmalar

\begin{tabular}{|l|l|l|l|}
\hline Yazar(lar) ve Yıl & Veri & Analiz Yöntemi & Bulgular \\
\hline $\begin{array}{l}\text { Buguk ve Brorsen } \\
\text { (2003) }\end{array}$ & iMKB & $\begin{array}{l}\text { Birim kök, GPH testi, } \\
\text { varyans oranı testi }\end{array}$ & Zayıf formda etkin \\
\hline Atan vd. (2009) & iMKB & $\begin{array}{l}\text { Birim kök testleri, } \\
\text { ELW }\end{array}$ & Getiriler öngörülemez \\
\hline $\begin{array}{l}\text { Özcan ve Yılancı } \\
(2009)\end{array}$ & $\begin{array}{l}\text { IMKB 100 Bileşik, iMKB } \\
\text { Ulusal 50, iMKB Ulusal } \\
\text { 30, iMKB Sınai, iMKB } \\
\text { Mali ve iMKB Hizmet }\end{array}$ & Birim kök testleri & Getiriler öngörülebilir \\
\hline $\begin{array}{l}\text { Özer ve Ertokatlı } \\
(2010)\end{array}$ & IMKB & $\begin{array}{l}\text { BDS, NEGM, Lyapunov } \\
\text { Üssü, Hinich Bispectral }\end{array}$ & Getiriler öngörülebilir \\
\hline
\end{tabular}


Tablo 1. Türkiye Finansal Piyasaları Çerçevesinde Getiri Öngörülebilirliği veya Zayıf Formda Piyasa Etkinliğiyle İlgili Çalışmalar (Devamı)

\begin{tabular}{|c|c|c|c|}
\hline Çevik (2012) & IMKB'deki 10 sektör & $\begin{array}{l}\text { MLP, ELW tahmin ve } \\
\text { FIGARCH }\end{array}$ & Etkin piyasa değil \\
\hline $\begin{array}{l}\text { Kapusuzoğlu } \\
\text { (2013) }\end{array}$ & İMKB & Birim kök testleri & Zayıf formda etkin değil \\
\hline $\begin{array}{l}\text { Zeren ve Konuk } \\
(2013)\end{array}$ & Gelişmekte olan ülkeler & Birim kök testleri & $\begin{array}{l}\text { Türkiye piyasasında } \\
\text { getiriler öngörülemez }\end{array}$ \\
\hline Gözbaşı (2014) & BisT & Birim kök testleri & Zayıf formda etkin \\
\hline Yang vd. (2015) & MIST ülkeleri & $\begin{array}{l}\text { Fourier KSS, Fourier } \\
\text { Panel KSS, Ardışık Panel } \\
\text { Seçim Metodu }\end{array}$ & $\begin{array}{l}\text { Türkiye piyasasında } \\
\text { getiriler öngörülemez }\end{array}$ \\
\hline Erdem (2016) & $\begin{array}{l}\text { Avrupa ve Asya-Pasifik } \\
\text { pazarları }\end{array}$ & Birim kök testleri & $\begin{array}{l}\text { Türkiye piyasasında } \\
\text { getiriler öngörülebilir }\end{array}$ \\
\hline Yücel (2016) & $\begin{array}{l}\text { BisT kapsamında } \\
\text { hesaplanan } \\
\text { endekslerden seçilen } 22 \\
\text { endeks }\end{array}$ & Birim kök testleri & Getiriler öngörülemez \\
\hline $\begin{array}{l}\text { Alper ve Aydoğan } \\
(2017)\end{array}$ & Bist & Portföy oluşturma & Getiriler öngörülebilir \\
\hline Doğan (2017) & BisT & ANOVA & Zayıf formda etkin \\
\hline $\begin{array}{l}\text { Gemici ve Polat } \\
(2018)\end{array}$ & MIST ülkeleri & $\begin{array}{l}\text { Furuoka (2016) birim kök } \\
\text { testi }\end{array}$ & $\begin{array}{l}\text { Türkiye piyasasında } \\
\text { rassal yürüyüş hipotezi } \\
\text { geçerli değil }\end{array}$ \\
\hline $\begin{array}{l}\text { Sülkü ve Ürkmez } \\
\text { (2018) }\end{array}$ & $\begin{array}{l}\text { BiST Hizmet, Sınai } \\
\text { Teknoloji, Mali } \\
\text { endeksleri }\end{array}$ & $\begin{array}{l}\text { BDS testi, dönüştürülmüş } \\
\text { genişlik analizi ve } \\
\text { korelasyon boyutu } \\
\text { yöntemi }\end{array}$ & Getiriler öngörülebilir \\
\hline Pabuçcu (2019) & BisT 100 & $\begin{array}{l}\text { Makine öğrenme } \\
\text { algoritmaları }\end{array}$ & Getiriler öngörülebilir \\
\hline $\begin{array}{l}\text { Bektur ve Aydın } \\
\text { (2019) }\end{array}$ & $\begin{array}{l}\text { BisT } 100 \text { (Getiri) endeksi } \\
\text { ve alt endeksleri hizmet, } \\
\text { mali, sınai ve teknoloji } \\
\text { endeksleri }\end{array}$ & Birim kök testleri & Zayıf formda etkin \\
\hline $\begin{array}{l}\text { Kayral ve Alagöz } \\
(2019)\end{array}$ & G20 ülkeleri & Birim kök testleri & $\begin{array}{l}\text { Türkiye piyasasında } \\
\text { getiriler öngörülemez }\end{array}$ \\
\hline
\end{tabular}

Bu çalışma getiri öngörülebilirliğini diğer bir ifadeyle zayıf formdaki piyasa etkinliğini hem endeksler bazında karşılaştırması hem de karşılaştırma yöntemi bakımından Türkiye finansal piyasaları üzerine gerçekleştirilen çalışmalardan farklılaşmaktadır. Ayrıca martingale fark hipotezi için geliştirilen otomatik portmanteau testini de Türk varlık getirileri üzerinde kullanan ilk çalışmalardandır. Çalışmanın bu yönleriyle literatüre önemli katkılar sağlayacağı düşünülmektedir.

\section{Metodoloji}

Bu çalışmada getiri öngörülebilirliği için Escanciano ve Lobato (2009a) tarafından geliştirilen otomatik portmanteau testi uygulanmıştır. Ljung ve Box'un (1978) portmanteau testi varlıkların getiri öngörülebilirliğini değerlendirmek için finans literatüründe sıklıkla kullanılan bir yöntemdir. Fakat söz konusu yöntem küçük örneklemlerde yetersiz özelliklerden dolayı başarısız sonuçlar ortaya koymaktadır. Ayrıca gecikme uzunluğu veya bekleme süresi için öznel seçimler gerektirdiğinden, bu durum da küçük örneklem özelliklerini daha da zayıflatmaktadır. Lobato vd. (2001) modifiye edilmiş portmanteau test yöntemini geliştirerek söz konusu küçük örneklem özelliklerini geliştirmeye çalışmıştır. 
Gecikme uzunluğunu veya bekleme süresini öznel olarak seçme probleminin üstesinden gelmek için Escanciano ve Lobato (2009a), gecikme uzunluğu seçiminin verilere bağlı bir şekilde tamamen otomatik olarak yapıldığı otomatik portmanteau (AQ) testini geliştirmişlerdir. Charles vd. (2011) Monte Carlo uygulaması gerçekleştirdikleri çalışmada $A Q$ testinin oldukça yeterli küçük örneklem özellikleri gösterdiğini ve getiri öngörülebilirliği için diğer portmanteau testlerinden daha başarılı olduğunu belirtmişlerdir.

Portmanteau test istatistiği 1 numaralı denklemdeki gibi yazılmaktadır:

$$
Q_{p}=T \sum_{i=1}^{p} \hat{p}^{2}(i)
$$

1 numaralı denklemde yer alan $\hat{p}(i)$, getiri oranını zaman serisi $Y_{t}^{\prime}$ nin $i$ mertebesindeki örnek otokorelasyonunu ifade etmektedir. $Y_{t}^{\prime}$ nin koşullu değişen varyans özelliği göstermesi durumunda Lobato vd. (2001) denklem 2'de yer alan test istatistiğinin kullanılması gerektiğini belirtmişlerdir:

$$
Q_{p}^{*}=T \sum_{i=1}^{p} \tilde{p}^{2}(i), \quad \tilde{p}(i)=\hat{\gamma}^{2}(i) / \hat{\tau}(i)
$$

2 numaralı denklemde yer alan $\hat{\gamma}^{2}(i), Y_{t}^{\prime}$ nin $i$ mertebesindeki örnek otokovaryansını, $\hat{\tau}(i)$ ise $Y_{t}^{2 \prime}$ nin $i$ mertebesindeki örnek otokovaryansını ifade etmektedir.

Testi uygulayabilmek için p'nin seçilmesi gerekmektedir. Escanciano ve Lobato (2009), p'nin optimal değerinin tamamen verilere bağıı bir şekilde belirlendiği otomatik testi önermişlerdir. Sıfır hipotezi altında $\chi_{1}^{2}$ dağılımını asimptotik olarak takip eden söz konusu test istatistiği 3 numaralı denklemdeki gibi yazılmaktadır:

$$
A Q=Q_{\tilde{p}}^{*}
$$

3 numaralı denklemde yer alan $\tilde{p}, \tilde{p}=\min \left\{p: 1 \leq p \leq d ; \quad L_{p} \geq L_{h}, \quad h=1,2, \ldots, d\right\}$ şeklinde, $L_{p}$, $L_{p}=Q_{p}^{*}-\pi(p, T, q)$ şeklinde yazılmaktadır. Ifadelerde yer alan $d$ ise sabit üst sınırdır. AIC ve BIC arasında bir denge olan $\pi(p, T, q)$ penalty terimi 4 numaralı denklemdeki gibi yazılmaktadır:

$$
\pi(p, \quad T, q)= \begin{cases}p \log (T) & , \max _{1 \leq i \leq d} \sqrt{T}|\tilde{p}(i)| \leq \sqrt{2,4 \log (T)} \\ 2 p & , \max _{1 \leq i \leq d} \sqrt{T}|\tilde{p}(i)|>\sqrt{2,4 \log (T)}\end{cases}
$$

AQ istatistikleri, $\chi_{1}^{2}$ dağılımın $100(1-\alpha)$. yüzdeliği olan $\chi_{1, \alpha}^{2}$ asimptomatik kritik değerinden büyükse, getirilerin öngörülemeyeceğini belirten sıfır hipotezi $\alpha$ anlamlılık düzeyinde reddedilir.

Yukarıda tarif edilen $A Q$ testi, popülasyon otokorelasyon değerlerinin 0 olup olmadığını test ederek getiri öngörülebilirliğinin istatistiksel önemini değerlendirmek için kullanılır. Bununla birlikte, getiri öngörülebilirliğinin büyüklüğünü temsil eden etki büyüklügünün de değerlendirilmesi önemlidir. $A Q$ istatistiği, $Y_{t}$ 'nin örnek otokorelasyon karelerinin optimal sıra (örneklem büyüklüğüne göre ölçeklendirilerek) ile toplamı olduğundan, yüksek $A Q$ istatistik değeri, yüksek getiri öngörülebilirliğini gösterir. Ayrıca $A Q$ testi tüm örnek otokorelasyonlarını eşit ağırlıklarla optimum düzeye getirir (Charles vd., 2015: 12).

\section{Veri ve Ampirik Bulgular}

Bu çalışmada Borsa İstanbul bünyesinde yer alan 19 birincil sektöre ait endeksin 04.07.200007.02.2020 tarihleri arasındaki günlük verileri kullanılmıştır. Söz konusu sektörler Yiyecek ve İçecek (XGIDA), Ulaştırma (XULAS), Turizm (XTRZM), Tekstil ve Deri (XTEKS), Teknoloji (XUTEK), Sigorta (XSGRT), Sanayi (XUSIN), Toptan Satış ve Perakende Ticaret (XTCRT), Kimyasal, Petrol ve Plastik (XKMYA), Hizmet (XUHIZ), Mali (XUMAL), Elektrik (XELKT), Basit Metaller (XMANA), Metal Ürünler ve Makineler (XMESY), Metal Harici Mineral Ürünler (XTAST), Holding ve Yatırımlar (XHOLD), Bilgi Teknolojileri (XBLSM), Bankalar (XBANK), Odun, Kağıt ve Baskı (XKAGT) olarak uygun veri tarihlerine göre belirlenmiştir. Investing internet sitesinden elde edilen günlük kapanış fiyatlarının doğal logaritmik birinci farkları alınarak günlük getiriler hesaplanmıştır 
(Erişim Tarihi: 08.02.2020). Ayrıca logaritmik getiriler yakınsama probleminden kaçınmak için 100 ile çarpılmıştır. Tablo 2 çalışma kapsamındaki sektörlere ait endekslerin logaritmik günlük getirileri ile ilgili tanımlayıcı istatistikleri göstermektedir.

Tablo 2. Tanımlayıcı İstatistikler

\begin{tabular}{|l|c|c|c|c|c|c|}
\hline \multicolumn{1}{|c|}{ Veriler } & Ö.B. & Ort. & S.S. & Skewness & Kurtosis & JB \\
\hline GXGIDA & 4918 & 0,058 & 2,033 & $-0,169$ & 12,824 & $0,000^{* * *}$ \\
\hline GXULAS & 4918 & 0,068 & 2,477 & $-0,156$ & 8,124 & $0,000^{* * *}$ \\
\hline GXTRZM & 4918 & 0,020 & 2,713 & 0,078 & 11,675 & $0,000^{* * *}$ \\
\hline GXTEKS & 4918 & 0,050 & 1,920 & $-0,906$ & 14,972 & $0,000^{* * *}$ \\
\hline GXUTEK & 4918 & 0,044 & 2,242 & $-0,310$ & 11,903 & $0,000^{* * *}$ \\
\hline GXSGRT & 4918 & 0,060 & 2,254 & $-0,275$ & 23,741 & $0,000^{* * *}$ \\
\hline GXUSIN & 4918 & 0,053 & 1,749 & $-0,333$ & 15,622 & $0,000^{* * *}$ \\
\hline GXTCRT & 4918 & 0,058 & 2,008 & $-0,109$ & 18,245 & $0,000^{* * *}$ \\
\hline GXKMYA & 4918 & 0,050 & 2,028 & $-0,034$ & 11,586 & $0,000^{* * *}$ \\
\hline GXUHIZ & 4918 & 0,040 & 1,854 & $-0,149$ & 14,659 & $0,000^{* * *}$ \\
\hline GXUMAL & 4918 & 0,042 & 2,311 & $-0,021$ & 9,6970 & $0,000^{* * *}$ \\
\hline GXELKT & 4918 & 0,018 & 2,244 & $-0,127$ & 10,724 & $0,000^{* * *}$ \\
\hline GXMANA & 4918 & 0,068 & 2,389 & $-0,148$ & 9,5138 & $0,000^{* * *}$ \\
\hline GXMESY & 4918 & 0,050 & 2,059 & $-0,273$ & 11,729 & $0,000^{* * *}$ \\
\hline GXTAST & 4918 & 0,046 & 1,632 & $-0,464$ & 15,694 & $0,000^{* * *}$ \\
\hline GXHOLD & 4918 & 0,037 & 2,168 & $-0,085$ & 10,704 & $0,000^{* * *}$ \\
\hline GXBLSM & 4918 & 0,023 & 2,265 & $-0,152$ & 10,938 & $0,000^{* * *}$ \\
\hline GXBANK & 4918 & 0,043 & 2,718 & 0,207 & 52,301 & $0,000^{* * *}$ \\
\hline GXKAGT & 4918 & 0,049 & 2,070 & $-0,338$ & 8,886 & $0,000^{* * *}$ \\
\hline
\end{tabular}

Not: JB testinin sıfır hipotezi ilgili verinin normal dağıldığı varsayımı üzerine kurulmuştur. ${ }^{* * *}$ simgesi $1 \%$ önem düzeyini belirtmektedir. Ö.B., Ort., S.S. ve JB sırasıyla örneklem büyüklüğü, ortalama, standart sapma ve Jarque-Bera'ya ait olasılık değerlerini ifade etmektedir.

Tablo 2'ye bakıldığında en fazla ortalama getiriye Basit Metaller ve Ulaştırma sektör endekslerini sahip olduğu, en fazla oynaklığa ise Bankalar sektör endeksinin sahip olduğu görülmektedir. Skewness değerleri Turizm ve Bankalar sektörleri dışındaki sektör endeks getirilerinin normal dağılıma göre sola çarpık olduğunu, Kurtosis değerleri ise bütün sektör endeks getirilerinin dağılımlarının normal dağılıma göre leptokurtik (sivri tepeli ve şişman kuyruklu) olduğunu göstermektedir. Hem skewness hem de kurtosis değerleri bütün getiri serilerinin normal dağılmadığını ifade etmektedir. Normallik için gerçekleştirilen JB testi sonuçları da \%1 önem düzeyinde sıfır hipotezinin reddedileceğini, diğer bir ifadeyle getiri serilerinin normal dağılmadığını belirtmektedir. Otomatik portmanteau testi, analiz gerçekleştirilecek olan verilerin durağan olmasını gerektirdiğinden sektör endeksleri getiri serilerinin durağanlık durumları Phillips ve Perron (1988) tarafından geliştirilen Phillips-Perron (PP) birim kök testi ile incelenmiştir. PP birim kök testi sonuçları Tablo 3 'te yer almaktadır.

Tablo 3. PP Test Sonuçları

\begin{tabular}{|l|c|c|c|c|}
\hline \multirow{2}{*}{ Veriler } & \multicolumn{2}{|c|}{ Sabit } & \multicolumn{2}{c|}{ Sabit ve Trendli } \\
\cline { 2 - 5 } & t-istatistiği & Olasılık & t-istatistiği & Olasılık \\
\hline GXGIDA & $-70,394$ & $0,000^{* * *}$ & $-70,397$ & $0,000^{* * *}$ \\
\hline GXULAS & $-69,211$ & $0,000^{* * *}$ & $-69,207$ & $0,000^{* * *}$ \\
\hline GXTRZM & $-63,483$ & $0,000^{* * *}$ & $-63,478$ & $0,000^{* * *}$ \\
\hline GXTEKS & $-66,206$ & $0,000^{* * *}$ & $-66,196$ & $0,000^{* * *}$ \\
\hline GXUTEK & $-68,344$ & $0,000^{* * *}$ & $-68,369$ & $0,000^{* * *}$ \\
\hline GXSGRT & $-69,434$ & $0,000^{* * *}$ & $-69,428$ & $0,000^{* * *}$ \\
\hline GXUSIN & $-69,481$ & $0,000^{* * *}$ & $-69,474$ & $0,000^{* * *}$ \\
\hline GXTCRT & $-71,854$ & $0,000^{* * *}$ & $-71,849$ & $0,000^{* * *}$ \\
\hline
\end{tabular}


Tablo 3. PP Test Sonuçları (Devamı)

\begin{tabular}{|l|l|l|l|l|}
\hline GXKMYA & $-71,087$ & $0,000^{* * *}$ & $-71,082$ & $0,000^{* * *}$ \\
\hline GXUHIZ & $-69,169$ & $0,000^{* * *}$ & $-69,162$ & $0,000^{* * *}$ \\
\hline GXUMAL & $-69,871$ & $0,000^{* * *}$ & $-69,862$ & $0,000^{* * *}$ \\
\hline GXELKT & $-66,524$ & $0,000^{* * *}$ & $-66,520$ & $0,000^{* * *}$ \\
\hline GXMANA & $-70,258$ & $0,000^{* * *}$ & $-70,251$ & $0,000^{* * *}$ \\
\hline GXMESY & $-68,553$ & $0,000^{* * *}$ & $-68,549$ & $0,000^{* * *}$ \\
\hline GXTAST & $-69,207$ & $0,000^{* * *}$ & $-69,200$ & $0,000^{* * *}$ \\
\hline GXHOLD & $-68,924$ & $0,000^{* * *}$ & $-68,918$ & $0,000^{* * *}$ \\
\hline GXBLSM & $-67,042$ & $0,000^{* * *}$ & $-67,023$ & $0,000^{* * *}$ \\
\hline GXBANK & $-74,601$ & $0,000^{* * *}$ & $-74,597$ & $0,000^{* * *}$ \\
\hline GXKAGT & $-67,346$ & $0,000^{* * *}$ & $-67,340$ & $0,000^{* * *}$ \\
\hline
\end{tabular}

Not: Sıfır hipotezi ilgili veride birim kök olduğunu, diğer bir ifadeyle verinin durağan olmadığını ve ${ }^{* * *}$ simgesi $1 \%$ önem düzeyini belirtmektedir.

Tablo 3’te yer alan durağanlık çıktılarına bakıldığında, bütün getiri serileri için \%1 önem düzeyinde sıfır hipotezinin reddedildiği, diğer bir ifadeyle veri setlerinin durağan olduğu anlaşılmaktadır. Bu sonuçlar çalışma kapsamında kullanılan sektör endeks getirileri ile analizler gerçekleştirilebileceğini belirtmektedir.

Getiri öngörülebilirliği açısından Türkiye'deki farklı sektörleri karşılaştırmak için bu çalışmada yaklaşık 520 günlük gözlem sayısından oluşan 2 yıllık alt örneklemler kullanılmıştır. Söz konusu veri büyüklüğünün ideal olduğu Charles vd. (2011) tarafından belirtilmiştir. Ayrıca 2 yıllık alt örneklem büyüklüğü değişen piyasa koşullarının etkilerini yakalamak için de uygundur (Charles vd., 2015: 15). illk alt örneklem 05.07.2000 ile 05.08.2002 tarihleri arasındaki getirileri kapsamaktadır. Diğer alt örneklemler 1 günlük ileri taşıma ile oluşturulmuştur. Bu işlem ilgili getiri serilerinin son elde ediliş tarihine kadar uygulanmıştır. Bu uygulamayla her bir sektör endeks getiri serisi için 4399 adet alt örneklem kümesi oluşturulmuş ve her bir alt örneklem kümesine otomatik portmanteau testi uygulanmıştır. Çalışma kapsamında kullanılan her bir sektör endeks getiri serisi için 4399 kez gerçekleştirilen otomatik portmanteau testi çıktıları Şekil 1'de gösterilmektedir.

Şekil 1. AQ Testi Çıktıları
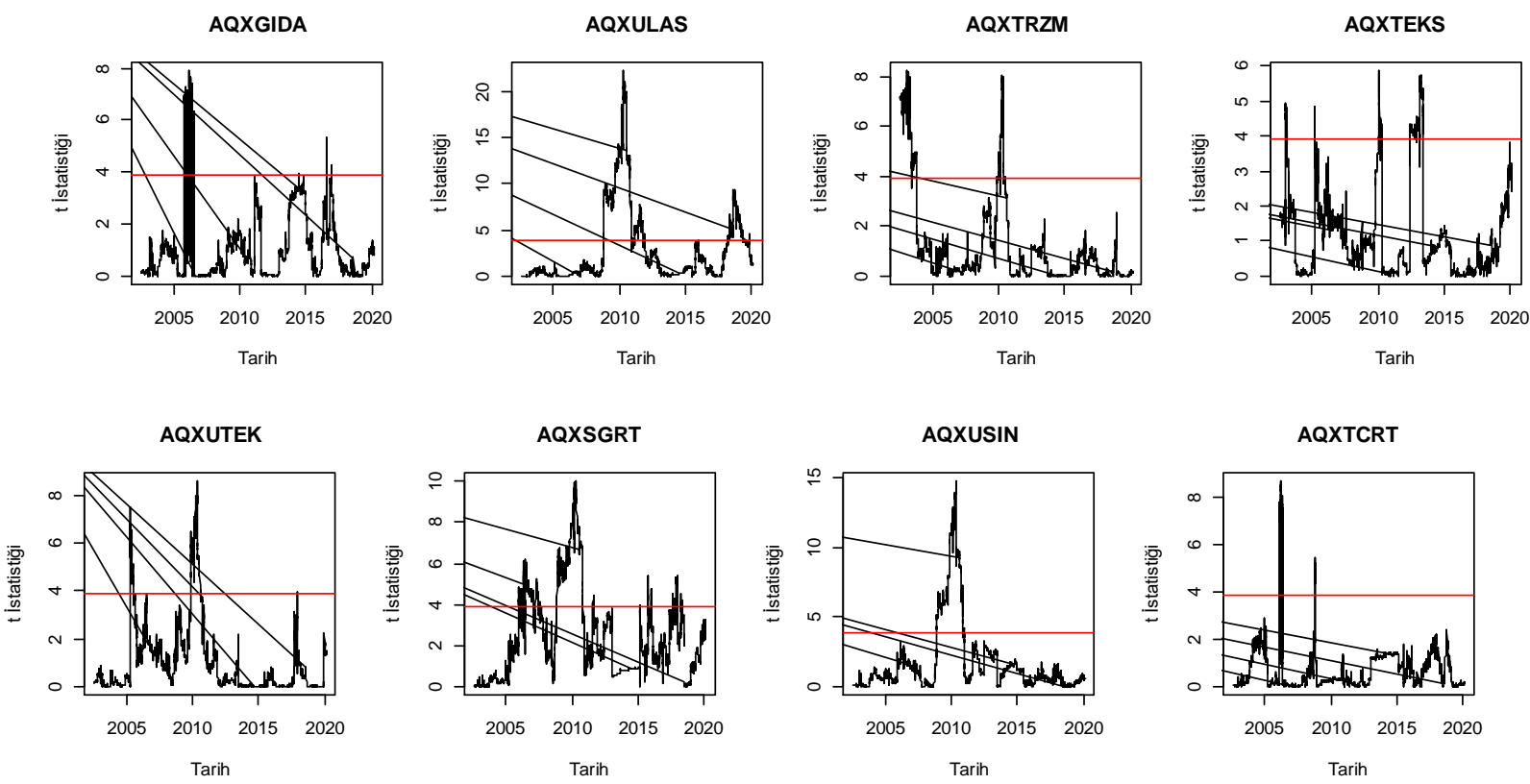
Şekil 1. AQ Testi Çıktıları (Devamı)

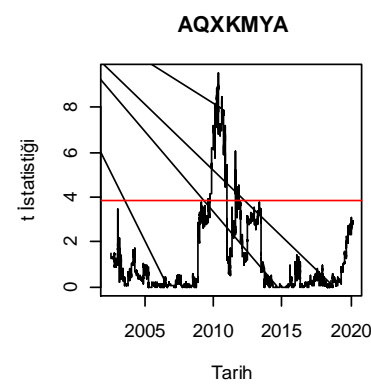

AQXMANA

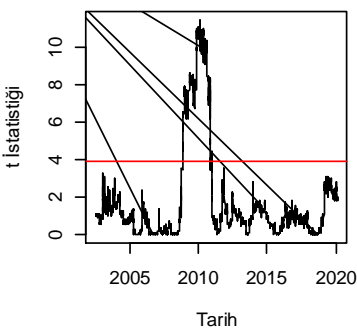

AQXBLSM

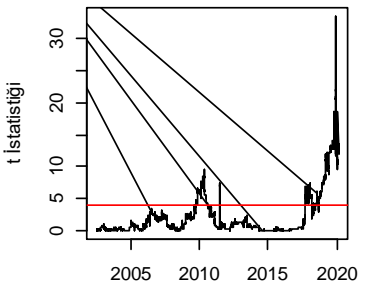

Tarih

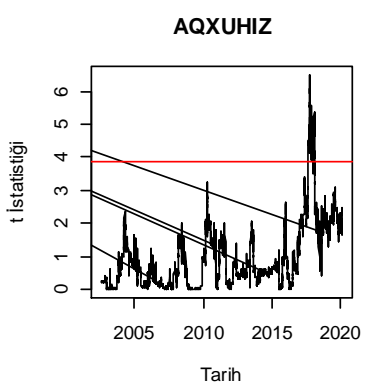

AQXMESY

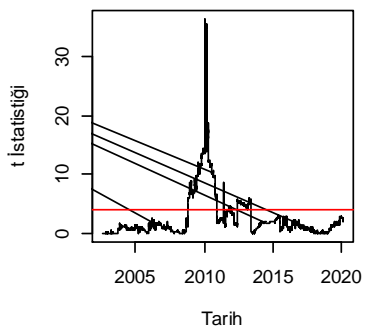

AQXBANK

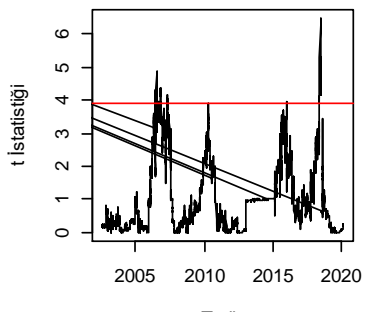

Tarih

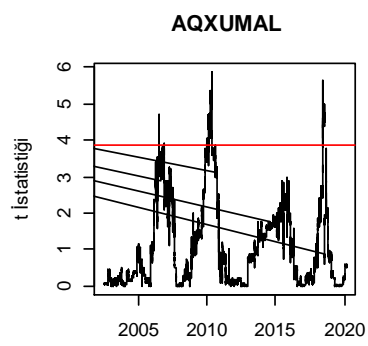

Tarih

AQXTAST

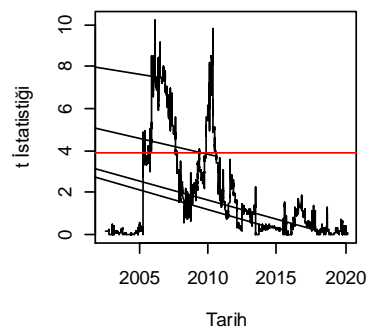

AQXKAGT

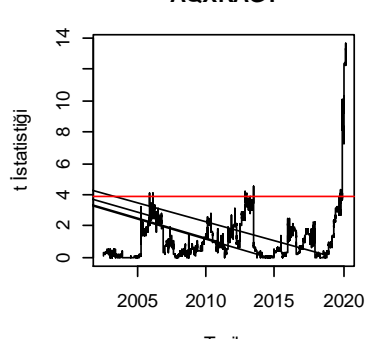

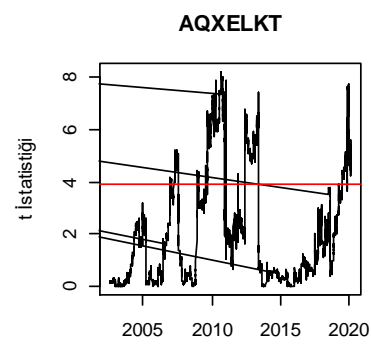

Tarih

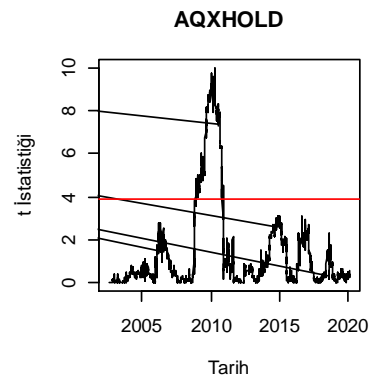

Not: Sıfır hipotezi getirilerin öngörülemez olduğunu belirtmektedir. Yatay çizgi \%5 önem düzeyinin asimptotik kritik değeri olan 3,89'u ifade etmektedir.

Şekil 1'de yer alan AQ sonuçlarını gösteren grafiklerdeki yatay çizgi \%5 önem düzeyindeki asimptotik kritik değer olan 3.89'u belirtmektedir. $A Q$ değerlerinin kritik değerden büyük olması sıfır hipotezinin reddedileceğini, diğer bir ifadeyle getirilerin öngörülebilir olduğunu ifade etmektedir. Kritik değerden küçük olan $A Q$ değerleri, sıfır hipotezinin kabul edileceği dolayısıyla getirilerin öngörülemeyeceğini belirtmektedir. Şekil 1'deki grafikler incelendiğinde her bir sektör endeksinin belirli dönemlerde getirilerinin öngörülebilir olduğu, belirli dönemlerde ise getirilerinin öngörülemez olduğu görülmektedir. Tablo 4 sektörler bazında getirilerin öngörülebilir olduğu gün sayılarını göstermektedir.

Tablo 4. Sektörler Bazında Tarihsel Fiyatlardan Yararlanılabilecek Gün Sayısı

\begin{tabular}{|c|c|c|c|}
\hline GXGIDA & GXBANK & GXTCRT & GXKAGT \\
\hline 52 & 75 & 79 & 81 \\
\hline GXUMAL & GXUHIZ & GXUTEK & GXTEKS \\
\hline 112 & 115 & 262 & 331 \\
\hline GXKMYA & GXTRZM & GXHOLD & GXUSIN \\
\hline 356 & 417 & 489 & 506 \\
\hline GXMANA & GXTAST & GXBLSM & GXMESY \\
\hline 525 & 704 & 777 & 830 \\
\hline GXELKT & GXSGRT & GXULAS & \\
\hline 854 & 884 & 1020 & \\
\hline
\end{tabular}


Tablo 4'te yer alan sonuçlar incelendiğinde, Yiyecek ve İçecek, Bankalar, Toptan Satış ve Perakende Ticaret ve Odun, Kağıt ve Baskı sektörlerinin diğer sektörlerden daha fazla getiri öngörülemezlik dönemleri sergilediği bulunmuştur. Bu sonuç söz konusu sektörlerin diğer sektörlere göre daha fazla zayıf formda etkin olduğunu göstermektedir. Ulaştırma, Sigorta, Elektrik ve Metal Ürünler ve Makineler sektörlerin ise diğer sektörlere göre daha fazla getiri öngörülebilir dönemlerine sahip olduğu ve dolayısıyla diğer sektörlere göre daha az zayıf formda etkin olduğu anlaşılmaktadır. Bu sonuçlar, bireysel ve kurumsal yatırımcılar ile portföy yöneticilerinin Ulaştırma, Sigorta, Elektrik ve Metal Ürünler ve Makineler sektörlerinde tarihsel fiyat hareketlerini kullanarak fiyat tahminlemesi konusunda daha başarılı sonuçlar elde edebileceklerini açık bir şekilde ortaya koymaktadır. Yiyecek ve İçecek, Bankalar, Toptan Satış ve Perakende Ticaret ve Odun, Kağıt ve Baskı sektörlerinde tarihsel fiyat hareketlerini kullanarak başarılı tahminler gerçekleştirilebilme şansı oldukça düşüktür.

\section{Sonuç}

Türkiye'deki farklı sektörleri getiri öngörülebilirliği diğer bir ifadeyle zayıf formdaki piyasa etkinliği açısından karşılaştırmak amacıyla gerçekleştirilen bu çalışmada, Borsa i̇stanbul bünyesinde yer alan 19 birincil sektör endeksinin 04.07.2000 ile 07.02.2020 tarihleri arasındaki günlük verileri kullanıımıştır. Bu amaç çerçevesi içerisinde ilgili veri setleri martingale fark dizisi özelliğini test etmek için Escanciano ve Lobato (2009a) tarafından geliştirilen, normal dağılmayan veri setlerinde oldukça başarılı sonuçlar veren ve aynı zamanda piyasanın etkinlik (etkinsizlik) veya varlık getirilerinin öngörülebilirlik derecesinin belirlenebilmesinde kullanılan test istatistiklerini de sağlayan otomatik portmanteau testi kullanılmıştır. Her bir sektör endeksi için gerçekleştirilen otomatik portmanteau test sonuçları Ulaştırma, Sigorta, Elektrik ve Metal Ürünler ve Makineler sektörlerinin diğer sektörlere göre daha fazla getiri öngörülebilir dönemlerine sahip olduğunu ve dolayısıyla diğer sektörlere göre daha az zayıf formda etkin olduğunu göstermiştir. Yiyecek ve içecek, Bankalar, Toptan Satış ve Perakende Ticaret ve Odun, Kağıt ve Baskı sektörlerinin ise getiri öngörülebilir dönemlerinin çok düşük olduğu, bu sektörlerin diğer sektörlere göre daha fazla zayıf formda etkin olduğu ulaşılan bir diğer önemli sonuçtur. Bu sonuçlar, bireysel ve kurumsal yatırımcılar ile portföy yöneticilerinin Ulaştırma, Sigorta, Elektrik ve Metal Ürünler ve Makineler sektörlerinde tarihsel fiyat hareketlerini kullanarak fiyat tahminlemesi konusunda daha başarılı sonuçlar elde edebilecekleri, Yiyecek ve içecek, Bankalar, Toptan Satış ve Perakende Ticaret ve Odun, Kağıt ve Baskı sektörlerinde ise başarı şanslarının oldukça düşük olduğu anlamına gelmektedir. Bundan sonra gerçekleştirilecek olan çalışmalar Türk finansal piyasalarında bulunan diğer varlıkların etkinliklerini karşılaştırmak üzere gerçekleştirilebilir.

\section{Beyan ve Açıklamalar (Disclosure Statements)}

1. Bu çalışmanın yazarı, araştırma ve yayın etiği ilkelerine uyduğunu kabul etmektedir (The author of this article confirms that her work complies with the principles of research and publication ethics).

2. Yazar tarafından herhangi bir çıkar çatışması beyan edilmemiştir (No potential conflict of interest was reported by the author).

3. Bu çalışma, intihal tarama programı kullanılarak intihal taramasından geçirilmiştir (This article was screened for potential plagiarism using a plagiarism screening program).

\section{Son Notlar}

1. Martingale süreç veya martingale fark için ayrıca bkz: Escanciano ve Lobato (2009b). 


\section{Kaynaklar}

Alper, D., \& Aydoğan, E. (2017). The profitability of contrarian strategy: Borsa Istanbul case. Muhasebe ve Finansman Dergisi, 74, 201-213.

Atan, S. D., Özdemir, Z. A., \& Atan, M. (2009). Hisse senedi piyasasında zayıf formda etkinlik: IMKB üzerine ampirik bir çalışma. Dokuz Eylül Üniversitesi Iktisadi ve Idari Bilimler Fakültesi Dergisi, 24(2), 33-48.

Bektur, Ç., \& Aydın, M. (2019). Borsa İstanbul ve alt endekslerinde zayıf formda piyasa etkinliğinin analizi: Fourier yaklaşımı. Akademik incelemeler Dergisi, 14(2), 59-76.

Buguk, C., \& Brorsen, B. W. (2003). Testing weak-form market efficiency: Evidence from the Istanbul Stock Exchange. International Review of Financial Analysis, 12(5), 579-590.

Charles, A., Darne, O., \& Kim, J. H. (2011). Small sample properties of alternative tests for martingale difference hypothesis. Economics Letters, 110, 151-154.

Charles, A., Darne, O., \& Kim, J. H. (2015). Adaptive markets hypothesis for Islamic stock portfolios: Evidence from Dow Jones size and sector-indices. SSRN Working Paper. https://ssrn.com/abstract=2611472 (Erişim Tarihi: 10 Şubat 2020).

Charles, A., Darne, O., \& Kim, J. H. (2017). Adaptive markets hypothesis for Islamic stock indices: Evidence from Dow Jones size and sector-indices. International Economics, 151, 100-112.

Çevik, E. İ. (2012). İstanbul Menkul Kıymetler Borsası'nda etkin piyasa hipotezinin uzun hafıza modelleri ile analizi: Sektörel bazda bir inceleme. Journal of Yaşar University, 26(7), 4437-4454.

Doğan, H. H. (2017). Finans sektöründe sürpriz kara yatırımcı tepkisi: Türkiye'den bir uygulama Doğuş Üniversitesi Sosyal Bilimler Enstitüsü, Yüksek Lisans Tezi.

Erdem, M. S. (2016). Avrupa ve Asya-Pasifik hisse senedi pazarlarında zayıf formda pazar etkinliği ve takvim anomalileri. AiBÜ Sosyal Bilimler Enstitüsü Dergisi, 16(3), 149-166.

Escanciano, J. C., \& Lobato, I. N. (2009a). An automatic portmanteau test for serial correlation. Journal of Econometrics, $151,140-149$.

Escanciano, J. C., \& Lobato, I. N. (2009b). Testing the Martingale Hypothesis, (Eds.) K. Patterson, \& T. C. Mills, Palgrave Hand-book of Econometrics (ss. 972-1003). New York: Palgrave MacMillan.

Fama, E. (1965). The behaviour of stock market prices. Journal of Business, 38, 34-105.

Gemici, E., \& Polat, M. (2018). MIST borsalarında rassal yürüyüş hipotezi. Eskişehir Osmangazi Üniversitesi iiBF Dergisi, 13(1), 129-142.

Gözbaşı, O. (2014). Borsa İstanbul hisse senedi piyasasında doğrusal olmayan yöntemler ile piyasa etkinliğinin test edilmesi. Verimlilik Dergisi, 0(4), 7-18.

Investing, https://tr.investing.com (Erişim Tarihi: 08 Şubat 2020).

Kapusuzoğlu, A. (2013). Testing weak form market efficiency on the Istanbul Stock Exchange (ISE). International Journal of Business Management and Economic Research, 4(2), 700-705.

Kayral, I. E., \& Alagöz, H. M. (2019). G-20 üyesi ülke borsalarının zayıf formda piyasa etkinliğinin test edilmesi. Muhasebe Bilim Dünyası Dergisi, 21(3), 809-828.

Kim, J. H., Lim, K. P., \& Shamsuddin, A. (2011). Stock return predictability and the adaptive markets hypothesis: Evidence from century long U.S. Data. Journal of Empirical Finance, 18, 868-879.

Lim, K. P., \& Brooks, R. D. (2010). The evolution of stock market efficiency over time: A survey of the empirical literature. Journal of Economic Surveys, 24, 1-40.

Ljung, G. M., \& Box, G. E. P. (1978). On a measure of lack of fit in time series models. Biometrika, 65, $297-303$.

Lobato, I. N., Nankervis, J. C., \& Savin, N. E. (2001). Testing for autocorrelation using a modified Box-Pierce Q test. International Economic Review, 42, 187-205.

Özcan, B., \& Yılancı, V. (2009). Türk hisse senedi piyasasının zayıf formda etkinliğinin testi. iktisat işletme ve Finans, 24(274), 100-115.

Özer, G., \& Ertokatlı, C. T. (2010). Chaotic processes of common stock index returns: An empirical examination on Istanbul Stock Exchange market. African Journal of Business Management, 4(6), 1140-1148.

Pabuçcu, H. (2019). Borsa endeksi hareketlerinin makine öğrenme algoritmaları ile tahmini. Uluslararası iktisadi ve idari incelemeler Dergisi, 23, 179-190.

Phillips, P. C. B., \& Perron, P. (1988). Testing for a unit root in time series regression. Biometrika, 75(2), 335-346. 
Samuelson, P. A. (1965). Proof that properly anticipated prices fluctuate randomly. Industrial Management Review, 6 , 41-49.

Sülkü, S. N., \& Ürkmez, E. (2018). Hisse senedi getirilerinde doğrusal olmayan dinamikler: Türkiye'den kanıtlar. Uluslararası iktisadi ve Idari Incelemeler Dergisi, 18. EYI Special Issue, 473-484.

Yang, G. J. A., Lee, C., \& Lee, C. H. (2015). Random walk in the MIST. Journal of Asia-Pacific Business, 16(2), 92-104.

Yücel, Ö. (2016). Finansal piyasa etkinliği: Borsa İstanbul üzerine bir uygulama. International Review of Economics and Management, 4(3), 107-123.

Zeren, F., \& Konuk, F. (2013). Testing the random walk hypothesis for emerging markets: evidence from linear and nonlinear unit root tests. Romanian Economic and Business Review, 8(4), 61-71. 